\title{
Bipartite Laparoscopic Cholecystectomy: New Technique for Avoiding Bile Duct Injury in Difficult Cases
}

\author{
Ahmed E. Lasheen*, Khaled Safwat, Wesam Amr, Osama Gharib, Mostafa Baiomy, \\ Mohamed Riad, Basem Sieda \\ General and Laparoscopic Surgery Department, Zagazig University Hospital, Zagazig University, Zagazig, Egypt \\ Email: ${ }^{*}$ lasheenahmed@yahoo.com
}

Received 12 May 2014; revised 8 June 2014; accepted 16 June 2014

Copyright (C) 2014 by authors and Scientific Research Publishing Inc. This work is licensed under the Creative Commons Attribution International License (CC BY). http://creativecommons.org/licenses/by/4.0/ cC) (i) Open Access

\section{Abstract}

The incidence of bile duct injury in laparoscopic cholecystectomy (LC) is still two times greater compared to classic open surgery. This study offers new procedure to avoid this complication during LC. The gall bladder was divided into two parts above the Hartmann pouch and all contents were aspirated. Then, the distal part was dissected for short distance. The proximal part was dissected dome down until reaching to cystic duct which was tied or clipped and cut. J-vac drain was put in peritoneal cavity. Between September 2012 and October 2013, overall 77 patients (53 females and 24 males) with mean age of 49 years (between 23 and 67 years) underwent bipartite laparoscopic cholecystectomy. The mean operative time was 60 minutes (between 40 and 90 minutes). The dissection of both parts of gall bladder was safe and easy as close as possible from its wall. No biliary tract injuries were recorded during or after procedure and also at follow-up period (20 months). Bipartite laparoscopic cholecystectomy is safe, easy to do, and can avoid all complications especially bile duct injuries in difficult cases.

\section{Keywords}

Bipartite Laparoscopic Cholecystectomy, Difficult Cases

\section{Introduction}

For more than a century classical cholecystectomy has been a method of choice in surgical management of gallbladder diseases. Laparoscopic cholecystectomy introduced in the late eighties, has now become the gold

*Corresponding author.

How to cite this paper: Lasheen, A.E., Safwat, K., Amr, W., Gharib, O., Baiomy, M., Riad, M. and Sieda, B. (2014) Bipartite Laparoscopic Cholecystectomy: New Technique for Avoiding Bile Duct Injury in Difficult Cases. Surgical Science, 5, $252-257$. http://dx.doi.org/10.4236/ss.2014.56044 
standard and has taken the place of conventional cholecystectomy [1]. It is the choice of treatment for symptomatic gallstone disease [2]. Short hospitalization period and rapid return to normal activity, less postoperative pain, more acceptable cosmetic results and lesser morbidity and mortality rates, are the principle advantages of this technique. However, the incidence of bile duct injuries is two times greater when compared to open cholecystectomy [3]-[5]. Bile duct injuries, either in classic open or LC, may necessitate several consecutive operations and invasive procedures, causing fear and anxiety to all surgeons. The development of bile duct injuries following LC is not common but a serious complication resulting in long term morbidity [6]. Herein, we introduce a new technique, with the hope to prevent bile duct injuries during LC.

\section{Patients and Methods}

Seventy seven patients (53 females and 24 males) were included in this study at the general and laparoscopic surgery department, Zagazig University Hospital, Egypt from September 2012 through October 2013. Forty patients were suffering from acute cholecystitis not responding to medical treatment and shifted to surgical treatment (bipartite laparoscopic cholecystectomy). Thirty seven patients showed much adhesion and difficult anatomy with chronic cholecystitis converted to bipartite laparoscopic cholecystectomy during operation (Figure 1). The mean age was 49 years (between 23 and 67 years). This study was discussed and approved from ethical committee of Zagazig University at August 2012. All information about the technique was discussed with all patients, and all patients gave writing consent for inclusion of their data in this study.

Surgical technique: Under general anesthesia, 4 ports as classical laparoscopic cholecystectomy were inserted after pneumoperitoneum was achieved. The reusable retrieval bag was introduced into peritoneal cavity through port $10 \mathrm{~mm}$ and put under the inferior surface of the liver and its mouth near from the gallbladder. The adhesions around gallbladder were dissected. The gall bladder transected just above the Hartmann pouch dividing it into two parts. During this transaction of the gall bladder, its contents were aspirated and big stones put inside the reusable retrieval bag. The distal part of gall bladder (body and fundus) was dissected for short distance distally and then holding by grasper to push liver up. The proximal part of gall bladder (Hartmann pouch and cystic duct) was dissected as close as possible from the gall bladder wall, with looking from inside and outside the gall bladder, until reach to cystic duct, which was tied by extracorporeal pretied ligature (Vicryl No. 0) or clipped. We can put small tube inside the cystic duct during dissection to identifying it and protect the bile duct from injury. After that, the cystic duct was divided and put the excised part inside the reusable retrieval bag. Then, the

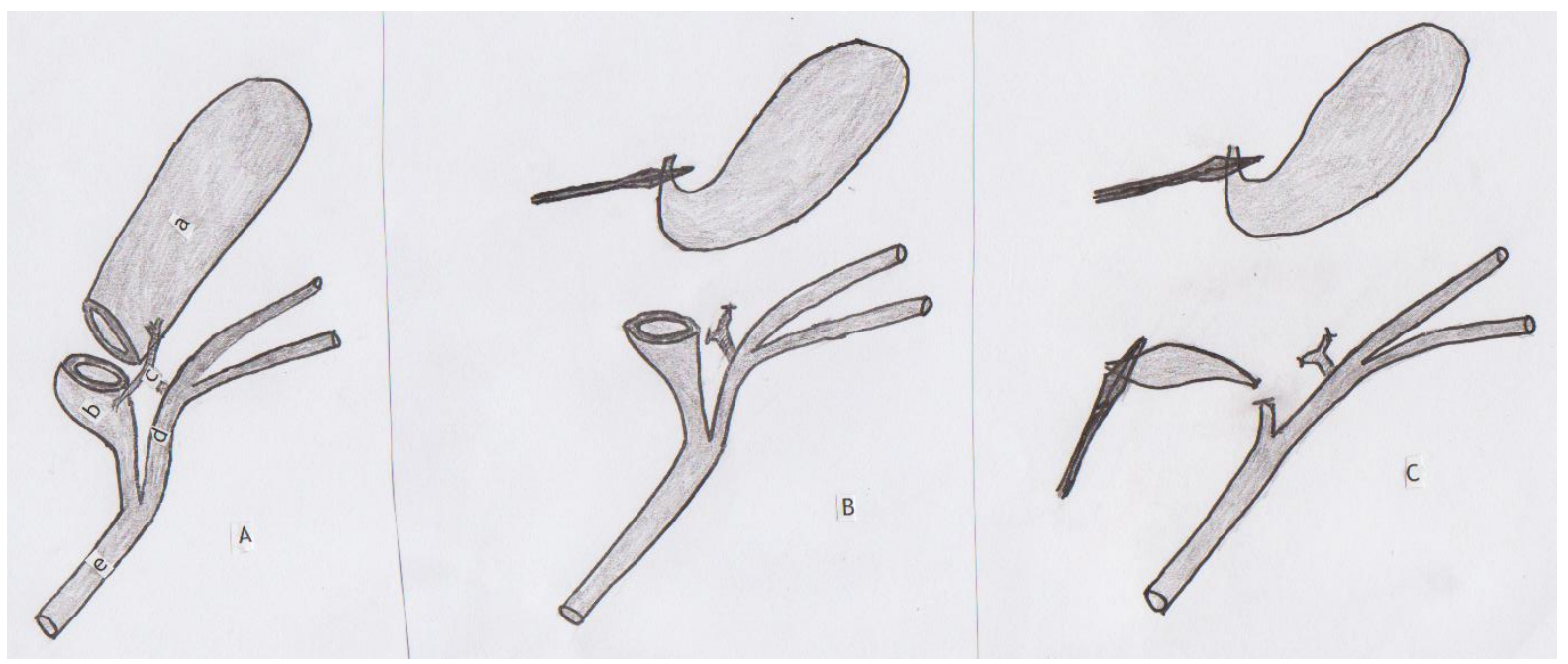

Figure 1. Diagram of bipartite laparoscopic cholecystectomy. (a) distal part of gall bladder formed of body and funds; (b) proximal part of gall bladder formed of cystic duct and Hartmann pouch; (c) cystic artery; (d) common hepatic duct; (e) common bile duct. (A) The gall bladder was cut above the Hartmann pouch dividing it to proximal and distal part. (B) The distal part was dissected for short distance as retrograde cholecystectomy dividing the cystic artery near the gall bladder wall, then pushed up by laparoscopic grasper to elevate the liver. (C) The proximal part was dissected close as possible from its wall by looking from inside, outside and behind it as fundus first cholecystectomy, until reaching to cystic duct which was ligated and cut. 


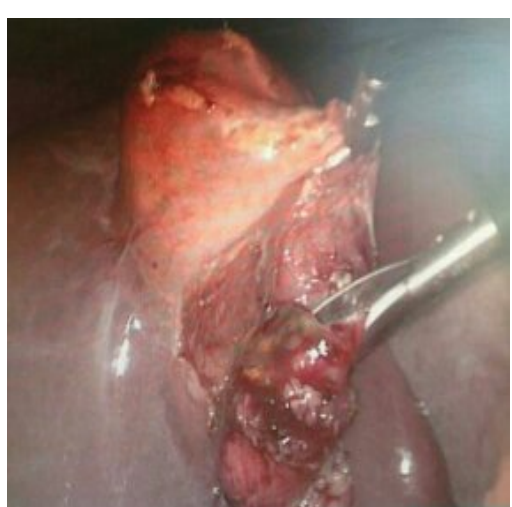

(a)

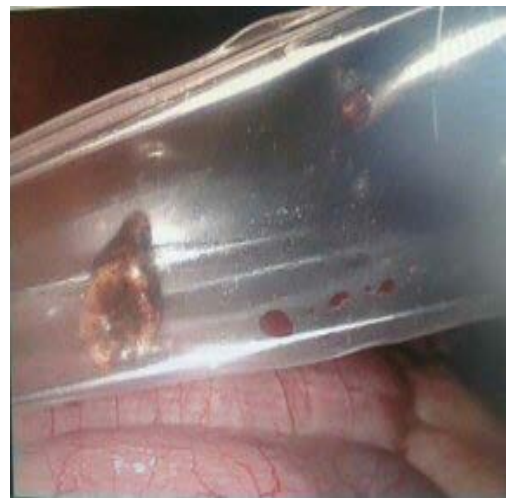

(d)

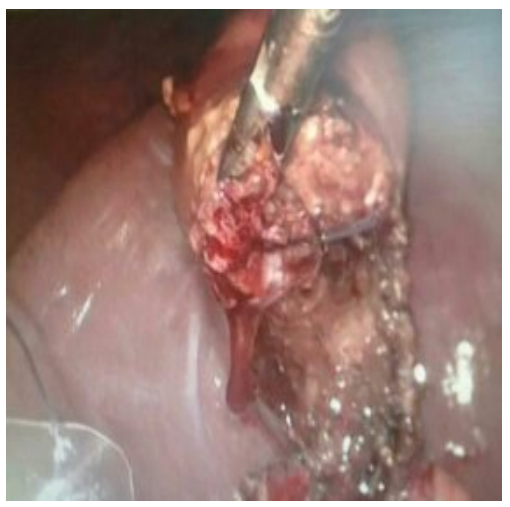

(g)

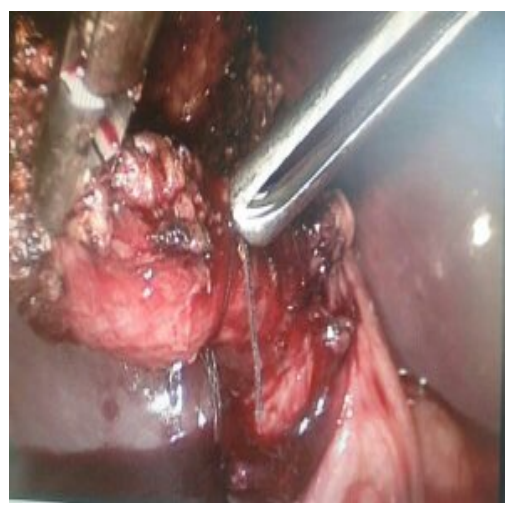

(j)

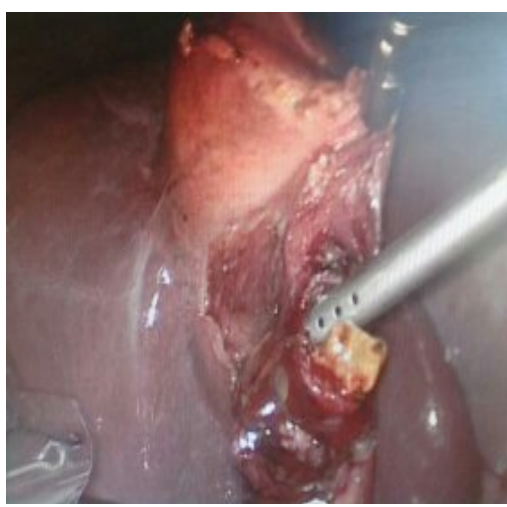

(b)

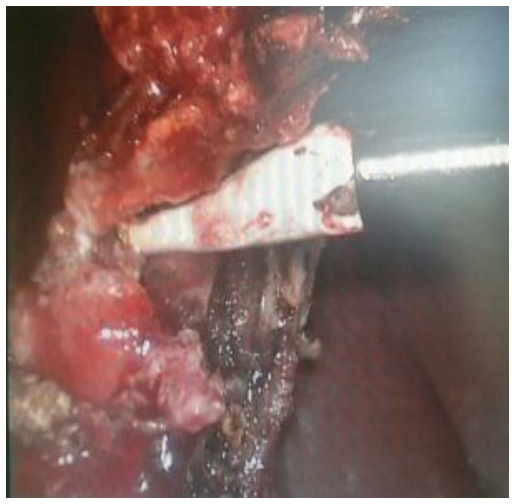

(e)

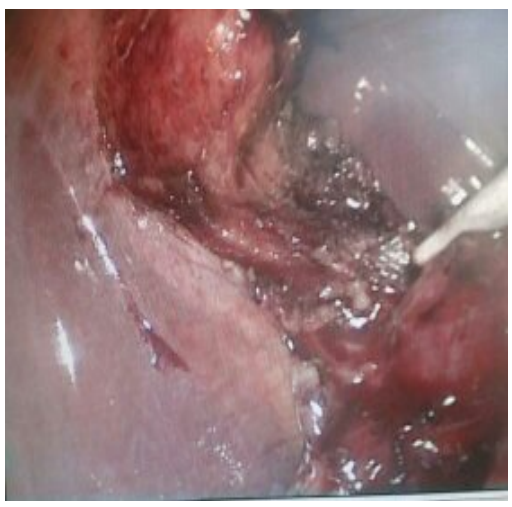

(h)

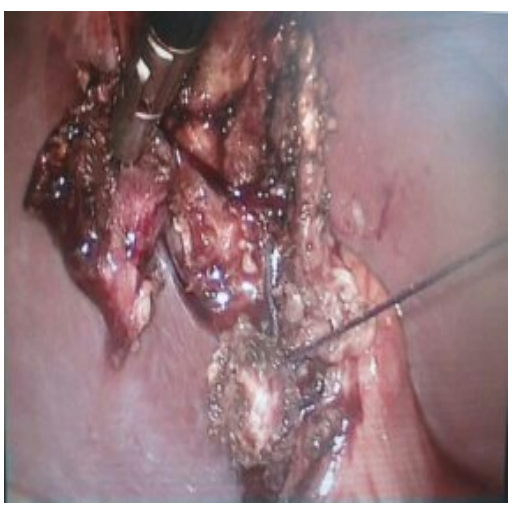

(k)

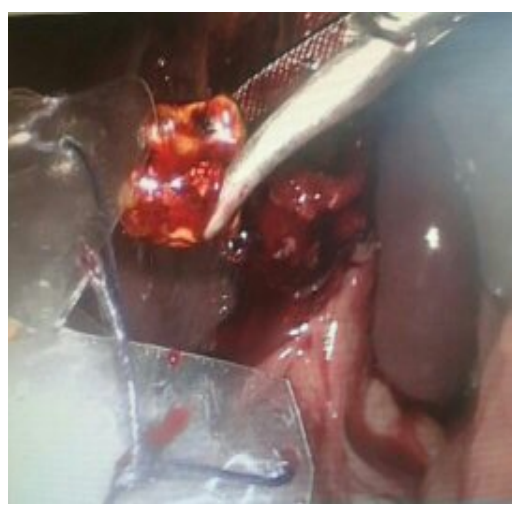

(c)

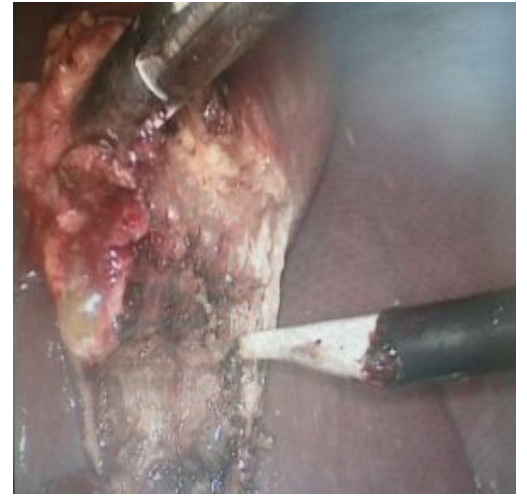

(f)

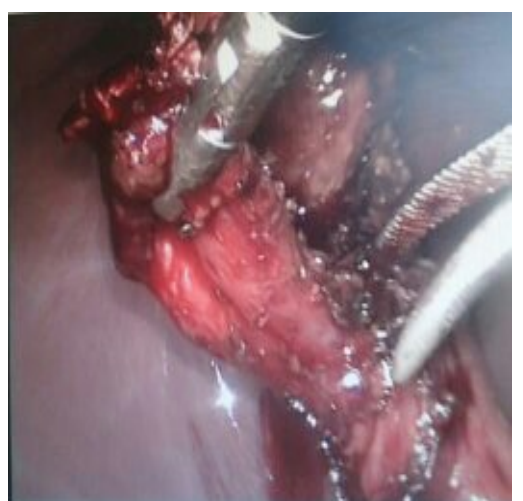

(i)

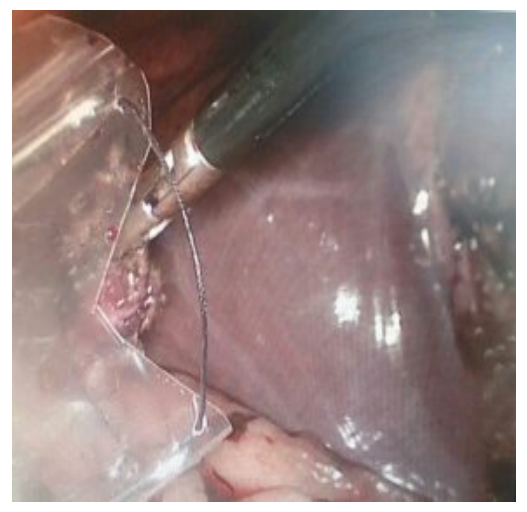

(l) 


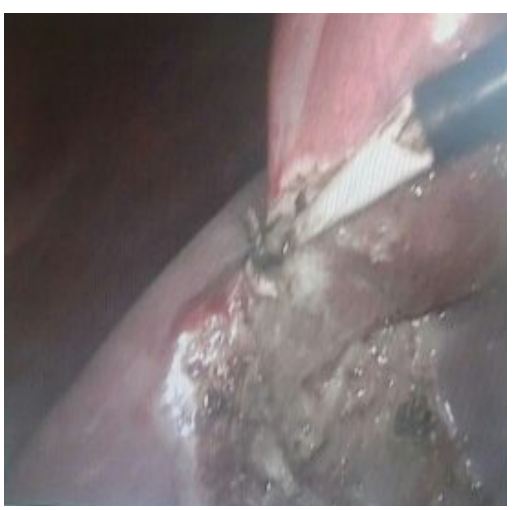

(m)

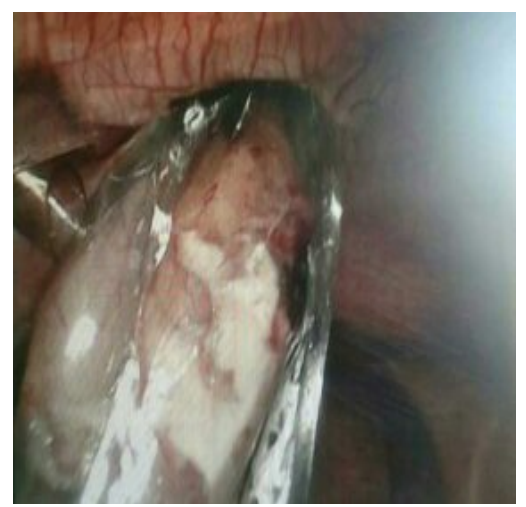

(n)

Figure 2. (a) The anterior wall of gall bladder was incised just above the Hartmann pouch by laparoscopic scissor, and after dissection of adhesion around it; (b) Suction of the gall bladder contents, and big stones impacted at the Hartmann pouch and cystic duct; (c) Big stone removed from proximal part (Hartmann pouch and cystic duct) and transferred to reusable retrieval bag; (d) Big stone put inside the retrieval bag, which present under the inferior liver surface; (e) Complete transaction of posterior gall bladder wall just above the Hartmann pouch, after complete evacuation of proximal part using hook; (f) Dissection of the distal part of gall bladder (body and fundus) for short distance; (g) This distal part push up by grasper to elevate the liver during dissection of proximal part; (h) The dissection of proximal part was started, by holding it by grasper and dissected by looking from inside and outside it and close as possible from its wall; (i) Dissection of the proximal part was completed (cystic duct was short and wide); (j) One extracorporeally pretied ligature was put around the cystic duct using Vicryl No. 0; (k) The proximal part cut distal to ligature; (l) The excised part(Hartmann pouch and cystic duct part) put inside the retrieval bag; (m) Then, the dissection of distal part was resumed and complete using hook; (n) The reusable retrieval bag with its contents (gall stones, excised proximal part, and distal part) was passed from abdominal cavity through port $10 \mathrm{~mm}$.

dissection of distal part (body and fundus) was resumed until completed, and put inside the retrieval bag which closed by extracorporeally pretied stitch and removal through port $10 \mathrm{~mm}$ from abdominal cavity. Suction and irrigation was done and J-Vac drain was inserted to peritoneal cavity through one $5 \mathrm{~mm}$ port. The port sites were closed and follow up period ranged from 7 to 26 months (mean 20 months).

\section{Results}

In 40 cases the patients suffered from acute cholecystitis and 37 cases from chronic cholecystitis with sever fibrosis around. The time of this procedure ranged from 45 to 90 minutes (mean, 60 minutes). The presence of retrieval bag is essential during this technique. There is some bleeding during transection of gall bladder, which controlled by using diathermy. The cystic artery was secured near of the gall bladder wall by using diathermy or clip during dissection of distal or proximal parts. The dissection of the proximal part (Hartmann pouch and cystic duct) is safe and easy after evacuation of its contents, and close as possible. There is no limitation to use this technique during laparoscopic cholecystectomy. The J-Vac drains were removed after 3 days in all cases. No wound infection was recorded in this patients group. No bile duct injuries were recorded intraoperative or postoperative or during follow up period (mean was 20 months) (Figure 2(a)-(n)).

\section{Discussion}

The incidence of bile duct injury appears to have stabilized at 0.4 to 0.6 percent, which is four times higher than that of open cholecystectomy [7] [8]. Many factors have been incriminated in occurrence of bile duct injuries during LC. These are mainly anatomical misidentification of main hepatic duct, right hepatic duct or of aberrant right hepatic duct, other anatomical variations or unidentifiable anatomy, surgeon's experience, technical difficulties, poor visualization of the operative field, acute and chronic inflammation of the gall bladder and local factors such as excessive hemorrhage and fat tissue [9] [10]. On the other hand, the problems related to the equipment have been accused [11]. However, misidentification of the anatomy and surgeon's experience seem to be preliminary [6] [12]. Bile duct injuries are associated with significant morbidity, prolonged hospitalization, increased financial burden, potential litigation and occasional mortality [5]. Some articles were published de- 
scribing recommended techniques to reduce bile duct injuries during LC [13]. Notable articles included reports by Hunter [14] recommending the use a 30 degree laparoscope and avoidance of tenting; Strasberg [15], who advocated the use of a critical view approach; Keto et al. [16], who introduced the dome down LC, with controversial results especially in risk cases. One study used the methylene blue to visualize the biliary ducts during LC after injection into the gall bladder to avoid duct injury [17]. But, this cannot be using in needed cases as acute cholecystitis or dense fibrosis around gall bladder or calcular obstruction of cystic duct. The roles of the intraoperative cholangiography and laparoscopic ultrasound remain controversial, which need for surgical experience, the inevitable prolongation of the operative time and the need for interpretation by an experienced radiologist [18]-[20]. In our technique (bipartite laparoscopic cholecystectomy), the gall bladder divided to two parts just above the Hartmann pouch, where the distal part (body and fundus of gallbladder) dissected for short distance to face cystic artery branches during entrance the gall bladder wall, which secured by diathermy or clip, far away from biliary ducts and hepatic vessels. Then, the proximal part (Hartmann pouch and cystic duct) dissected close as possible after looking from inside to detect any anatomical abnormalities before dissection starts. So, the dissection of proximal part do as dome down after opened it to see from inside.

\section{Conclusion}

With our technique, bile duct injuries can be avoided even with presence of risk factors (as anatomical abnormalities of biliary ducts, acute cholecystitis, severe chronic fibrosis, impacted stones within Hartmann pouch, and short cystic duct) during laparoscopic cholecystectomy.

\section{References}

[1] Mrksic, M.B., Farkas, E., Cabafi, Z., Komlos, A. and Sarac, M. (1999) Complications in Laparoscopic Cholecystectomy. Medicinski Pregled Journal, 52, 253-257.

[2] Gronroos, J.M., Hamalainen, M.T., Karvonen, J., Gullichsen, R. and Laine, S. (2003) Is Male Gender a Risk Factor for Bile Duct Injury during Laparoscopic Cholecystectomy? Langenbeck’s Archives of Surgery, 388, 261-264. http://dx.doi.org/10.1007/s00423-003-0407-1

[3] Ahrendt, S.A. and Pitt, H.A. (2001) Surgical Therapy of Iatrogenic Lesions of Biliary Tract. World Journal of Surgery, 25, 1360-1365. http://dx.doi.org/10.1007/s00268-001-0124-2

[4] Archer, S.B., Brown, D.W., Smith, C.D., Branum, G.D. and Hunter, J.G. (2001) Bile Duct Injury during Laparoscopic Cholecystectomy. Results of National Survey. Annals of Surgery, 234, 549-559. http://dx.doi.org/10.1097/00000658-200110000-00014

[5] Flum, D.R., Koepsell, T., Heagerty, P., Sinanan, M. and Dellinger, E.P. (2001) Common Bile Duct Injury during Laparoscopic Cholecystectomy. Adverse Outcome or Preventable Error? Archives of Surgery, 136, 1287-1292. http://dx.doi.org/10.1001/archsurg.136.11.1287

[6] Tsaalis, K.G., Chritoforidis, E.C., Dimitriadis, C.A., Kalfadis, S.C., Botsios, D.S. and Daduokis, J.D. (2003) Management of Bile Duct Injury during and after Laparoscopic Cholecystectomy. Surgical Endoscopy and Other Interventional Techniques, 17, 31-37. http://dx.doi.org/10.1007/s00464-001-9230-3

[7] Hobbs, M.S., Mai, Q., Knuiman, M.W., Fletcher, D.R. and Ridout, S.C. (2006) Surgeon Experience and Trends in Intraoperative Complications in Laparoscopic Cholecystectomy. British Journal of Surgery, 93, 844-849. http://dx.doi.org/10.1002/bjs.5333

[8] Nuzzo, G., Giuliante, F., Giovannini, I., Ardito, F., D’Acapito, F., Vellone, M., Murazio, M. and Capelli, G. (2005) Bile Duct Injury during Laparoscopic Cholecystectomy: Results of an Italian National Survey on 56591 Cholecystectomies. Archives of Surgery, 140, 986-989. http://dx.doi.org/10.1001/archsurg.140.10.986

[9] Calvete, J., Sabater, L., Camps, B., Verdu, A., Gomez-Portilla, A., Tonico, M.A., Flor, B., Cassinello, N. and Lledo, S. (2000) Bile Duct Injury Laparoscopic Cholecystectomy. Myth or Reality of the Learning Curve? Surgical Endoscopy, 14, 608-611. http://dx.doi.org/10.1007/s004640000103

[10] Johnson, S.R., Koehler, A., Pennington, I.K. and Hanto, D.W. (2000) Long-Term Results of Surgical Repair of Bile Duct Injuries Following Laparoscopic Cholecystectomy. Surgery, 128, 668-677. http://dx.doi.org/10.1067/msy.2000.108422

[11] Olsen, D. (1997) Bile Duct Injuries during Laparoscopic Cholecystectomy. Surgical Endoscopy, 11, 133-138. http://dx.doi.org/10.1007/s004649900315

[12] Krahenbuhl, L., Sclabas, G., Wente, M.N., Schafer, M., Schlumpf, R. and Buchler, M.W. (2001) Incidence, Risk Factors and Preventin of Biliary tract Injuries Laparoscopic Cholecystectomy in Switzerland. World Journal of Surgery, 
25, 1325-1330. http://dx.doi.org/10.1007/s00268-001-0118-0

[13] Fullum, T.M., Downing, S.R., Ortega, G., Chang, D.C., Oyetunji, T.A., Kirk, K.V., Tran, D.D., Wood, I., Cornwell, E.E. and Tuner, P.L. (2013) Is Laparoscopy a Risk Factor for Bile Duct Injury during Cholecystectomy? Journal of the Society of Laparoendoscopic Surgeons, 17, 365-370. http://dx.doi.org/10.4293/108680813X13654754535638

[14] Hunter, J.G. (1991) Avoidance of Bile Duct Injury during Laparoscopic Cholecystectomy. The American Journal of Surgery, 162, 71-76. http://dx.doi.org/10.1016/0002-9610(91)90207-T

[15] Strasberg, S.M. (2002) Avoidance of Biliary Injury during Laparoscopic Cholecystectomy. Journal of Hepato-Biliary-Pancreatic Surgery, 9, 543-547. http://dx.doi.org/10.1007/s005340200071

[16] Kato, K., Matsuda, M., Onodera, K., Kobayashi, T., Kasai, S. and Mito, M. (1994) Laparoscopic Cholecystectomy from Fundus Downward. Surgical Laparoscopy \& Endoscopy Journal, 4, 373-374. http://dx.doi.org/10.1097/00019509-199410000-00012

[17] Sari, Y.S., Tunali, V., Tomaoglu, K., Karagoz, B., Guney, A.I. and Karago, I.Z. (2005) Can Bile Duct Injuries Be Prevented? A New Technique in Laparoscopic Cholecystectomy. BMC Surgery, 5, 14-17. http://dx.doi.org/10.1186/1471-2482-5-14

[18] Giger, U., Ouaissi, M., Schmitz, S.f., Krahenbuhl, S. and Krahenbuhl, L. (2011) Bile Duct Injury and Use of Cholangiography during Laparoscopic Cholecystectomy. British Journal of Surgery, 3, 391-396. http://dx.doi.org/10.1002/bjs.7335

[19] Zha, Y., Chen, X.R., Luo, D. and Jin, Y. (2010) The Prevention of Major Bile Duct Injuries in Laparoscopic Cholecystectomy: Experience with 13,000 Patients in a Single Center. Surgical Laparoscopy Endoscopy and Percutaneous Techniques, 6, 373-383.

[20] Machado, N.O. (2011) Biliary Complications Post Laparoscopic Cholecystectomy: Mechanism, Preventive Measures, and Approach to Management: A Review. Diagnostic and Therapeutic Endoscopy Journal, 12, 1155-1164. 
Scientific Research Publishing (SCIRP) is one of the largest Open Access journal publishers. It is currently publishing more than 200 open access, online, peer-reviewed journals covering a wide range of academic disciplines. SCIRP serves the worldwide academic communities and contributes to the progress and application of science with its publication.

Other selected journals from SCIRP are listed as below. Submit your manuscript to us via either submit@scirp.org or Online Submission Portal.
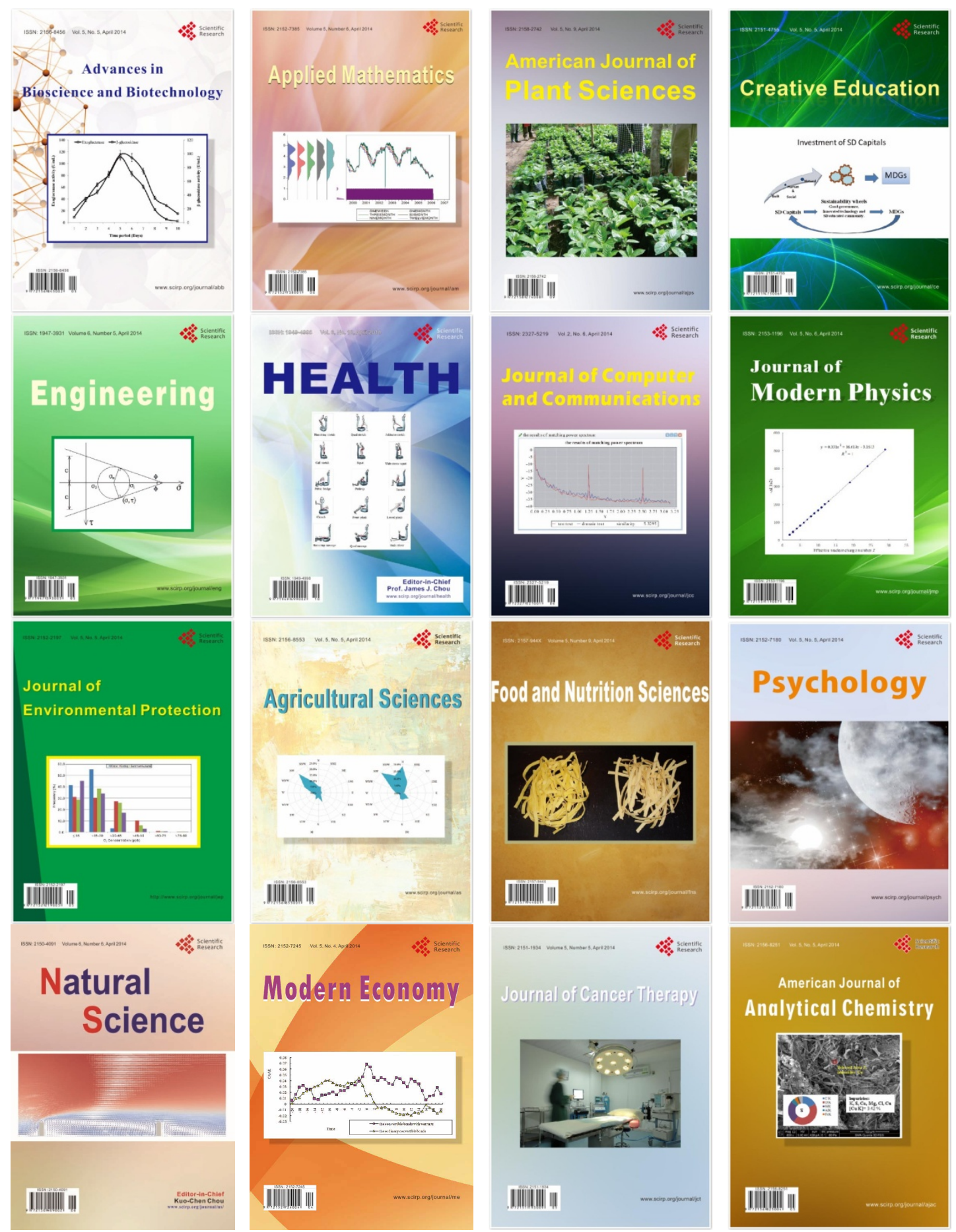